\title{
ETNISITAS DAN RADIO KOMERSIAL STUDI TERHADAP PROGRAM SIARAN BETAWI DI BENS RADIO DAN PROGRAM SIARAN JAWA DI RADIO CEMERLANG Zaenal Abidin Eko Putro ${ }^{1)}$ dan Gibran Maulana Ibrahim \\ Prodi Penerbitan (Jurnalistik), Politeknik Negeri Jakarta (PNJ), Kampus UI, Depok Email: ${ }^{\text {zaenalaep@yahoo.com }}$
}

\begin{abstract}
Commercial radio which contains ethnical broadcasting program is different from community radio that focuses only on a particular ethnic community problem as well as ethnic community issues. Although commercial radio broadcasts ethnical community program just like other community radio does so, goal of braodcasing ethnicity in both radio forms remain unsimilar. This paper departs from this problem and trays to respond it.

This paper is based on a field research with its qualitative method that organized by investigating two radio stations in Jakarta' greater area, namely MPM Radio Cemerlang Depok and Bens Radio Jakarta. One of the research findings is that ethnic voices broadcasted in both radios deals with commercial goal to gain profit as radio broadcasting enable to gain such profit or capital. However, broadcasting ethnicity program in radio has the goal to connect both radio audiences with their own culture background.
\end{abstract}

Key words: radio, commercial radio, ethnicity, radio audience and radio positioning

\begin{abstract}
Abstrak
Radio komersial yang memuat siaran bernuansa etnis amatlah berbeda dengan keberadaan radio komunitas. Perbedaan itu paling tidak ditinjau dari unsur perangkat siaran dan isi siaran. Sebagai radio yang menyuarakan suara komunitas, memang keberadaan radio swasta komersial juga samasama berpeluang mengangkat siaran komunitas. Hanya pertanyaannya apakah radio swasta komersial juga sama kedudukannya dengan radio komunitas dalam hal pemenuhan kebutuhan untuk komunitas tertentu. Paper ini berusaha merespon masalah terkait terpenuhi atau tidaknya kebutuhan komunitas dalam siaran radio komersial.

Dengan menggunakan metode kualitatif, penelitian ini menyasar siaran bernuansa Betawi di Bens Radio dan program siaran bernuansa Jawa di Radio Cemerlang. Dua radio ini dipilih berdasarkan lokasi stasiun radionya dan audience mereka yang berada di Jabodetabek. Dua stasiun radio tersebut sampai hari ini masih secara aktif mengudarakan siaran-siaran bernuansa etnis yang dikemas dalam berbagai bentuk. Berdasarkan hasil pencarian data dapat dikatakan bahwa elemen etnisitas yang dibangun oleh kedua radio tersebut memiliki keterkaitan erat dengan makanisme industri dan perniagaan yang dijalankan kedua radio tersebut. Suara etnisitas dikumandangkan untuk menetapkan posisi (positioning) radio di antara radio yang lain serta juga untuk mengakomodir kerinduan akan budaya etnis para pendengarnya.
\end{abstract}

Kata kunci: radio, radio komersial, etnisitas, pendengar radio dan penetapan posisi (positioning)

\section{PENDAHULUAN}

Keberadaan radio sebagai salah satu jenis media massa yang bercorak audio masih dapat dirasakan keberadaannya walau terjangan dari media massa online dan media massa bergambar (televisi) semakin tidak terhindarkan. Keberadaan radio begitu vital terutama pada era propaganda yang sangat fenomenal setalah Perang Dunia I hingga diproduksinya televisi secara massal. Sinyalemen ini setidaknya dapat mengacu pada sebuah film berjurul "Good Morning Vietnam!" (1987), yang dibintangi almarhum Robin William. Di film itu digambarkan betapa 
penyiar radio (diperankan Robin William) mampu membangkitkan semangat para tantara di tengah ketidakpastian situasi dalam medan pertempuran di Vietnam.

Model penyiaran radio semacam itu, mengobarkan semangat dan menyebarkan propaganda, barangkali kalau sekarang dapat disejajarkan dengan radio publik, radio yang melayani kepentingan negara. Jika dibandingkan dengan radio di Indonesia, maka tepatnya barangkali seperti RRI. Sebagaimana termaktub dalam UU No 32/2002 tentang Penyiaran, setidaknya terdapat tiga model radio yang beredar, yaitu radio publik (RRI), radio komersial serta radio komunitas. Masingmasing dari ketiga model radio tersebut mempunyai karakteristiknya sendirisendiri.

Radio komersial walaupun kelihatannya jarang diakses publik, paling tidak ditengarai terlibas dari maraknya jenis media elektronik lainnya, ternyata peminatnya masih cukup banyak. Setidaknya jika melihat dari bertahannya radio-radio komersial di tengah hebatnya platform media akibat proses digitalisasi belakangan ini. Radio-radio komersial itu dituntut pula untuk berkreasi serta berinovasi dalam isi siarannya. Kreasikreasi siaran radio komersial ini sangat menarik jika diamati karena terkadang menampilkan unsur-unsur kekhasannya, termasuk kekhasan lokal.

Di tengah maraknya media massa elektronik berbentuk visual dan juga media massa bercorak digital, keberadaan media massa bercorak audio seperti radio masih layak diperhitungkan. Ukuran sederhananya paling tidak dapat diamati dari dibutuhkannya radio oleh masyarakat sebagai saluran informasi, hiburan dan komersial di saat bersamaan dengan dilakukannya aktivitas lain seperti berkendara, bekerja di rumah dan seterusnya. Keunikannya, dan sekaligus keunggulannya, pada bidang teknologi suara (audio) membuat media ini lebih dirasakan kemudahan dalam mengaskesenya dan menikmatinya ketimbang media-media massa jenis lainnya.

Selain menitikberatkan pada informasi, hiburan dan saluran komersial, ternyata terdapat fenomena yang cukup tentang siaran radio ini. Salah satu hal yang menarik adalah dimunculkannya unsur etnis dalam muatan siarannya. Untuk melihat radio komersial di wilayah Jabodetabek yang metropolis dan kosmopolit, mungkin terbayang etnisitas tidak lagi penting dan malah sejauh mungkin dapat disembunyikan (melting pot). Semua etnis harus melebur menjadi satu kebudayaan dengan menyatu pada satu kebudayaan metropolis. Namun dalam kenyataannya, masih dapat ditemukan unsur-unsur etnisitas dalam kemodernan dan kekosmopolitan tersebut yang harus dipreservasi mengikuti konsep salad bowl, bukan asilimasi melainkan integrasi. Dua istilah tersebut dikenal amat kental melekat pada proses gerakan pembebasan di Amerika Serikat (Mahfouz, 2013: 2).

Artikel ini, yang merupakan hasil penelitian dari skema Dosen Pemula yang didanai BOPTN PNJ 2016, mencoba untuk mengeksplorasi keberadaan radio komersial terkait dengan isi siarannya. Salah satu isi siaran yang menarik untuk dilihat adalah siaran berunsur etnisitas. Radio komersial dengan isi siarannya seperti ini dapat dilihat pada Bens Radio yang memuat siaran etnis Betawi serta Radio MPM Cemerlang yang memuat siaran etnis Jawa. Keduanya ingin dilihat seperti apa program yang dijalankan serta dampaknya terhadap komunitas yang diunggah dalam isi siaran radio tersebut. Penelitian untuk paper ini dapat berlangsung

\section{Kerangka Teori}

\section{Etnisitas dan Radio Komersial}

Seperti telah disinggung di muka, siaran radio merupakan sarana siaran audio bersifat hiburan dan informatif yang dapat dengan mudah diakses oleh masyarakat. Menurut bunyi Pasal 1 ayat 4 Ketentuan Umum Peraturan Komisi Penyiaran 
Indonesia Nomor 01/P/KPI/03/2012 tentang Pedoman Perilaku Penyiaran, penyiaran radio adalah media komunikasi massa dengar yang menyalurkan gagasan dan informasi dalam bentuk suara secara umum dan terbuka. Ia hadir dengan mengudarakan program yang teratur dan berkesinambungan. Pengertian singkat ini setidaknya cukup memadai untuk mendefinisikan media elektronik jenis ini.

Dalam perkembangannya, radio siaran radio ini bervariasi, termasuk juga status dan kedudukannya secara hukum. Di Indonesia paling tidak dikenal radio swasta dan juga radio nasional. Untuk yang disebut terakhir ini sering dialamatkan pada radio publik yang mana sering dialamatkan kepada Radio Republik Indonesia (RRI), sementara radio-radio swasta sering disebut juga radio komersial.

\section{Radio Komersial}

Dalam perjalanannya, tidak dipungkiri bahwa ternyata radio komersial tidak sepi dari lahan mendulang keuntungan. Ia kemudian menjelma menjadi organisasi profit dengan mengandalkan pemasukan iklan. Hal ini dipotret dengan baik oleh Vaizey, yang menyatakan bahwa stasiunstasiun radio komersial adalah contoh baik bagi berjalannya pengaruh bisnis kecil dalam masyarakat. Mereka mendukung bisnis lokal dengan menyediakan saranasarana yang sangat kuat untuk terbangunnya komunikasi dengan pelanggan lokal. Di samping itu radio komersial juga mampu memperkenalkan talenta kreatif ke publik yang lebih luas.

\section{Vaizey (2016: 2) menyatakan sebagai} berikut:

Commercial radio stations are excellent examples of the important economic role small businesses play in our economy, particularly in local communities. They support local businesses by giving them powerful means of communicating with local customers, and act as a breeding ground for the creative talent which go on to make the internationally renowned music, $T V$ and films that become the cornerstones of UK cultural identity.

Di sinilah perlu digarisbawahi, bahwa radio komersial memiliki banyak fungsi antara lain mengembangkan kehidupan individu, memperkuat rasa senasib dengan komunitas lokal, serta berperan dalam perputaran ekonomi di tingkat lokal. Unsur paling khas dari radio ini terletak pada kelokalannya. Betapa masih dimanfaatkannya media massa jenis ini, maka di Inggris umpamanya, sebuah riset tahun 2013 menunjukkan jumlah pendengar radio mencapai 35 juta pendengar per minggunya.

Dilihat dari jenis dan variasinya, maka radio komersial di sini berbeda jenisnya dengan radio komunitas. Ada beberapa karakteristik khusus yang membedakan radio komunitas dari jenis radio lainnya, termasuk dengan radio swasta komersial ini. Masduki (2007: iv-v) menjelaskan karakter radio komunitas sebagai berikut. Pertama, radio komunitas melayani kepentingan pendengar yang secara geografis terbatas. Kedua, radio komunitas adalah badan hukum yang pemilikan, pendanaan dan pengelolaannya dari komunitas itu sendiri. Ketiga, radio komunitas segenap olah siarannya tidak bermaksud mencari keuntungan dan keempat, radio komunitas biasanya bermula dari hobi bersiaran beberapa orang yang berhasil menarik audiensi masyarakat dan kemudian dimanfaatkan warga untuk kebutuhan bersama.

Satu lagi jenis radio, yaitu radio publik yang berbeda kedudukan dan fungsinya dengan kedua jenis radio di atas. Radio publik lebih bersifat luas dengan menjangkau lapisan masyarakat dari berbagai latar belakang. Jika radio komersial dan radio komunitas mengandung unsur kelokalan secara kuat, walaupun beberapa radio komersial juga membuka siaran dan cabangnya di daerah, namun radio publik dianggap kurang 
menampung unsur lokal. Sinyalemen ini mungkin saja bertentangan dengan kondisi riil di berbagai daerah sebab radio-radio publik di derah seperti RRI pun juga mewartakan siaran lokal.

Untuk memotret kedudukan radio public disinggung Patkin dan Stapleton (2012: 148) sebagai berikut:

The basic purpose of commercial forms of media such as newspapers, Internet portals and commercial television is to link consumers with advertisers. In contrast, public radio's role is to broadly inform, educate and entertain. An additional distinguishing feature of public radio is its mandate to cater to a wide spectrum of the community. Essentially, this responsibility held by public radio means it must consider the diversity of its audience in a way that is as inclusive as possible.

Sebagaimana disebutkan dalam pernyataan di atas, tujuan utama bentukbentuk media komersial seperti surat kabar, portal-portal internet dan televisi komersial adalah untuk menghubungkan antara konsumen dan pemilik pesan/iklan (advertiser). Gelombang elektromagnetik yang digunakan stasiun radio digunakan sebagai sarana untuk menyempaikan pesan-pesan tersebut. Radio seperti ini pun dikelola secara professional dengan pendekatan bisnis yang menguat. Sebaliknya, radio publik secara luas diarahkan untuk memberi informasi, memberikan edukasi dan hiburan. Hal lain yang membedakan radio publik dengan radio lain, radio publik memiliki mandat menyampaikan pesannya secara luas ke seluruh masyarakat. Radio publik juga tidak lepas dari kemungkinan menjadi corong suara pemerintah dengan agenda politik yang disandangnya. Di sinilah radio public dituntut untuk seterbuka mungkin, karena jangkauan gelombangnya yang begitu luas.

\section{Etnisitas dalam Radio Komersial}

Kemampuan pesawat radio antara lain mampu mengangkat berbagai isu, termasuk salah satunya isu komunitas marginal. Dalam beberapa segi, suara komunitas marjinal sering diabaikan. Maka dari itu, Cottle melihat media massa seperti radio juga dapat mengafirmasi keragaman sosial dan budaya dan juga menyediakan ruang krusial dengan cara menguatkan identitas-identitas masyarakat. Dengan mengutip Dayan (1998) dan Browne (1999), Cottle (2000: 3) selanjutnya menegaskan, organisasi media seperti halnya radio sulit menentukan pilihan apakah mengikuti standar universal, artinya murni berorientasi pasar yang dikendalikan oleh sistem, atau ia memilih tujuan khususnya sendiri, misalnya menyalurkan tuntutan dan keinginan komunitas lokal. Hal demikian inilah yang dihadapi kelompok etnis dalam perjuangannya untuk menuntut representasi pluralistic, salah satunya melalui radio.

Merujuk pada Cottle di atas, begitu penting membicarakan konsep etnisitas dalam siaran radio komersial, tidak terkecuali di Tanah Air. Hal ini mengingat dalam kesehariannya masyarakat Indonesia tidak lepas dari unsur kebaragaman. Atas fakta keberagaman yang melekat dalam tubuh masyarakat Indonesia dan keinginan untuk mempertahankan nasionalisme Indonesia, sebagian ahli menganggap multikulturalisme telah dijalankan. Dalam multikulturalisme, sebagai sebuah teori yang sekaligus kebijakan, terdapat keinginan untuk mengakui dan memberi peluang yang setara kepada setiap kelompok yang ada, tanpa membedabedakannya. Pengakuan dan pemberian peluang itu dapat saja melalui siaran radio. Selanjutnya, rekognisi atau pengakuan dan memperlakukan kelompok liyan secara setara belakangan menuntut adanya lembaga publik yang mengakui dan bukan mengabaikan kekhasan budaya, terutama untuk kelompok yang eksistensinya terikat dengan budaya yang dimilikinya. Tuntutan 
atas pengakuan politik (political recognition), meminjam Charles Taylor, akan kekhasan budaya ini sejalan dengan bentuk universalisme yang mendudukkan budaya dan konteks budaya yang amat bernilai dasar bagi kelompok tersebut (Putro \& Pratiwi, 2015: 17).

Menyinggung keberadaan siaran radio komersial bernuansa etnis, beberapa kajian mengenai hal ini telah dilakukan. British Broadcasting Corporation (BBC) misalnya, sejak awal tahun 2000an telah mengamati hal ini dan kemudian turut memopulerkan istilah multicultural broadcasting. Tidak dipungkiri bahwa menguatnya istilah ini tidak lepas dari fenomena menguatkan multikulutralisme di Eropa, termasuk Inggris. Walaupun belum ada definisi tunggal tentang istilah tersebut, namun setidaknya dua pengertian yang masuk dalam istilah tersebut, yaitu pertama, pemrograman siaran yang mencerminkan kenyataan multikultural dalam masyarakat, merefleksikan keberagaman budaya dan komunitas melalui seluruh program siarannya. Kedua, pemograman dengan perspektif khusus, namun tetap mengacu pada audience yang lebih luas yang sering disebut crosscultural programming (Hargrave, 2002: 32).

Tidak dapat dipungkiri bahwa isu representasi minoritas-minoritas etnis dalam media, juga telah masuk ke ranah pemasaran. Sejauh media menitikberatkan pada target komersial, maka kelompok social yang ada didefinisikan sebagai instrumen pasar dan dianggap sebagai segmen etnis. Pada lingkungan media komersial hari-hari ini, penting untuk memperhatikan bukan hanya integrasi media komersial dengan pihak audience, tetapi juga kelompok-kelompok pelanggan potensial, yang memiliki karakteristik umum. Sejauh komunitas didefinisikan sebagai kelompok yang memiliki karakteristik umum, mereka tetap akan dipandang sebagai unit-unit tepat untuk pemasaran atau periklanan. Maka dari itu, muncullah kesulitan bagi minoritas etnis dalam mempertahankan diri dari strategi segmentasi audience dalam pemasaran (Cankaya et all, 2000: 87)

Demikianlah telah diuraikan konsepkonsep penting terkait keunggulan dan sekaligus kelemahan radio komersial yang mengudarakan siaran bernuansa etnis. Uraian teori di sekitar etnisitas dan radio komersial demikian ini diharapkan berguna untuk mendukung pembahasan radio komersial dan etnisitas. Tantangan terbesarnya adalah apakah etnisitas yang disuarakan dalam radio tersebut dianggap sekadar piranti komersial, diangkat sebagai positioning etnisistas dalam siaran komersial atau juga terbaca sebagai komersialisasi etnisitas.

\section{Muatan Etnisitas di Radio MPM Cemerlang FM Depok dan Bens Radio Jakarta \\ Sejarah MPM Cemerlang FM Depok}

Radio MPM (Miftah Putra Mandiri) Cemerlang berdiri sejak tahun 2002 dengan tagline khasnya, "Radionya Kota Depok" dan berada di gelombang 107,2 FM. Berdirinya radio ini waktu itu atas prakars pemilik lama, yaitu seorang pengusaha yanga juga mengelola usaha Studio Foto Cemerlang yang berlokasi di Jalan Nusantara dan Jalan Margonda. Ijin radio ini dikeluarkan oleh Komisi Penyiaran Indonesia Daerah (KPID) Jawa Barat dengan nomor 241/K/KPIDJABAB/12/09.

Studio foto ini cukup terkenal di kawasan Depok dengan ciri khas warna kuning-nya. Pada saat radio ini masih menyatu kepemilikannya dengan studio foto ini, di ruangan studio foto ini selalu diperdengarkan siaran radio ini secara live. Saat pendirian dan beberapa saat setelahnya, siaran radio masih berisikan muatan bernuansa universal, pop atau Barat. Pada saat itu pun belum ada siaran bernuansa etnik.

Perkembangan radio ini terus berjalan walaupun hasilnya tidak terlalu spektakuler. Barulah di sekitar tahun 2010 kepemilikan radio berpindah ke kelompok MPM, sebuah holding company di bidang 
property, dan namanya pun sekarang menjadi Radio MPM Cemerlang. Lokasi siaranya pun berpindah, bukan lagi di Jalan Nusantara Depok, melainkan bergeser ke Jalan Arif Rahman Hakim, kantor MPM sendiri. Saat ini, radio ini memiliki 7 orang penyiar, antar lain Jimmy Arista, Windi, Andi, Ayu dan 3 orang penyiar baru.

\section{Alasan dan Makna siaran Jawa di NPM Cemerlang FM}

Nurjaman, selaku direktur radio ini menjelaskan, sekitar tahun 2006, setahun sebelum diakusisi oleh grup MPM, radio MPM Cemerlang mulai tindakan manajemen yang cukup bersejarah. Mereka memikirkan sebuah inovasi dalam siarannya. Maka muncullah siaran etnik. Perlu dicatat di sini bahwa siaran yang pada awal didirkan dibatasai pada siaran beretnik Sunda dan siaran beretnik Jawa. Alasan memunculkan inovasi ini sebagai jalan keluar dari ketatnya persaingan di jalur musik pop. Selanjutnya juga untuk menggenjot perolehan iklan dalam setiap bulannya. Alasan lain juga untuk meningkatkan rating sebab saat itu dilihat rating radio ini juga selalu di bawah.

"Nah akhirnya sebelum akuisisi, sekitar setahunan, ada program Pasundan dari jam 6-9 pagi. Terus dilanjutkan dengan diadakan program Campursari. Kami melakukan survai dan ternyata di Depok ini banyak kaum urban, dari Jawa Timur dan Jawa Tengah bekerja di sini. Itulah yang kita ambil coba pasar itu. Akhirnya kita coba perpaduan dari budaya, barat, dan pop-nya.” (Wawancara tanggal 1 September 2016).

Etnik Jawa terpresentasikan ke dalam siaran lagu-lagi campursari dan penggunaan Bahasa Jawa. Program Campursari adalah program berisi lagu jawa semuanya. Begitu pula penyiarnya juga harus mampu berbahasa Jawa. Program ini digarap secara serius mengingat program ini pun mempunyai fans-nya tersendiri. Program ini masih dipertahankan karena memang menurut pengelola radio ini, program ini mendapat respon yang cukup baik dari para pendengar yang diwakilinya. Penyiar khusus Berbahasa jawanya adalah Windi dan Jimmy Arista. Nurjaman menuturkan,

"Jadi waktu kita bertemu mereka, mereka senang, (mereka) merasa di rumah, dengan bahasa jawanya, dengan lagu-lagu jawanya. Programnya sekarang dari jam 12 siang sampai 3 sore setiap hari”.

Untuk menjadi penyiar program berhasa Jawa ini, tidak ada syarat khusus bagi penyiar, artinya tidak harus mengenal budaya Jawa secara mandalam. Hal yang ditekankan yang penting mampu berbahasa Jawa dan berpengalaman siaran, khususnya di bidang announcer. Hal ini karena penggunaan kemampuan Berhasa Jawa saja tanpa mampu siaran nantinya akan merasa kekikukan juga. Penyiar harus mengetahui bagaimana memainkan mixer dan sejenisnya.

Berjalannya program bernuansa etnik Jawa ini ternyata juga mendapat respon dari para pendengar. Untuk tokoh yang telah mengapresiasi terbilang cukup banyak, misalnya untuk siaran berbahasa Jawa memperoleh apresiasi dari paguyuban Jawa memberi pengelola radio ini sebuah piagam. Terlebih, Gubernur Jawa Barat Ahmad Heryawan, juga sempat talkshow di radio ini. Pemerintah daerah juga cukup memberi apresiasi karena sekarang baru menguat kesadaran pentingnya memperkuat budaya sendiri di tengah terjangan budaya Barat. Kebanyakan apresiasi dalam bentuk piagam. Hal lain yang cukup membanggakan ialah, walaupun taglinenya "Radionya Kota Depok", akan tetapi bukan hanya menjangkau wilayah Depok saja siarannya. Bahkan kalau malam mampu menjangkau sampai Sukabumi, dan Purwakarta.

Secara berurutan program siaran radio ini dapat dituliskan sebagai berikut. Mulai dari pukul 5-6 pagi acaranya adalah kuliah 
subuh, yang dilangsungkan secara live. Diteruskan pukul 6-9 pagi acaranya adalah Selamat Pagi Kota Depok, yang isinya berupa berita. Radio ini mengandalkan reporter yang menyiarkan berita-berita Depok yang juga diselingi lagu yang bercorak nge-beat. Dilanjutkan dari pukul 9-11 program Margonda, singkatan dari “mari goyang dangdut". Setelah itu dari pukul 12-15 inilah diisi dengan program Campursari.

Selepas program Campursari, kemudian jam 3-6 selamat sore Kotak Depok, dilanjutkan 6-8 itu acara Langgar, lagu tanpa selingan iklan. Isi lagunya campuran antara lagu pop Indo dan pop Barat. Pada pukul 8-10 itu acara pop Indonesia, hits Indonesia, dilanjutkan Jam 10-1 malam itu acara goyang MPM. Lagu-lagu dangdut dikhususkan untuk menghibur orang-orang yang begadang. Di samping itu, mereka juga mempunyai program off air yang ditujukan untuk menyasar anak muda seperti seminar, dengan edukasi anak-anak muda sembali diadakan acara live music.

Dalam menyikapi era digital ini, radio ini juga memperluas siarannya ke media digital dalam bentuk streaming. Sadar akan hal itu, pengelola radio ini juga berbenah. Dilakukanlah beberapa inovasi baru untuk mempertahankan eksistensi radio ini. Oleh sebab itu, tidak mengherankan jika siaran radio ini juga mempunyai pendengar setia di Malaysia, Singapura dan Saudi Arabia. Mereka ini adalah orang-orang Indonesia yang bekerja di sana. Mereka juga sering berkirim pesan mengenai pesan dan kesan terhadap radio MPM Cemerlang via pesan dan lain-lain.

\section{Sejarah Berdirinya Bens Radio}

Bens Radio, menurut company profilenya terbaru tahun 2016, didirikan pada tanggal 5 Maret 1990. Sejak berdirinya, radio ini memang mengusung budaya Betawi. Radio ini mengusung figur seniman besar Betawi, Benyamin Suaeb. Tokoh ini di akhir hayatnya sangat dinantinantikan kehadirannya di layar kaca saat membintangi sinetron $\mathrm{Si}$ Doel Anak
Sekolahan (SDAS) yang berperan sebagai Babe Sabeni.

Selain puluhan film yang diperankannya dan banyak lagu yang telah diciptakannya, salah satu peninggalan Benyamin Suaeb adalah Bens Radio ini. Radio yang di awal kemunculannya berada di gelombang AM 486 ini merupakan realisasi dari mimpi panjang Benyamin untuk mempunyai radio yang sebagian besar materinya berisikan budaya Betawi. Impian itu kemudian terealisasi saat Benyamin bertemu dengan rekan siaran baru, Fandi di Radio Arista, yang kini namanya berganti menjadi Kiss FM (https://www.merdeka.com/peristiwa/kisah -benyamin-sukses-tinggalkan-bisnis-radiountuk-anak-anaknya.html, diakses tanggal 18 Oktober 2016).

Diceritakan bahwa pada saat awal siaran, dalam sehari Bens Radio menerima 200 surat dari pendengar Bens Radio. Bahkan dalam waktu dua minggu siarannya, Bens Radio telah menerima 250 orang yang mendaftar sebagai anggota fans club. Benyamin fans club ini masih eksis hingga kini dan sering meramaikan stasiun radio ini yang beralamatkan di Jalan Jagakarsa No. 39 Jakarta Selatan.

Hingga kini, konsep, visi, dan misi Bens Radio masih belum berubah dari ide awal Benyamin, yaitu pelestarian budaya melalui media. Seiring dengan perkembangan zaman, Bens Radio terus berkembang dengan mengedepankan image sebagai radio berbudaya lokal yang berwibawa global. Perkembangan Bens Radio tidak lepas dari ide dan peran Biem Benyamin, anak ketiga Benyamin Suaeb yang memimpin sepeninggal Benyamin. Dalam sebuah wawancara, Biem Benyamin menuturkan, "hanya style kita Betawi sehingga dari presentasi musik kita punya kemudian bahasa tutur yang dibawakan oleh penyiar ada keharusan, kemudian insert, joke, itu semua bernuansa Betawi, itu yang mungkin tidak digarap oleh radio-radio lain.” (https://www.merdeka.com/peristiwa /kisah-benyamin-sukses-tinggalkan-bisnis- 
radio-untuk-anak-anaknya.html, diakses tanggal 18 Oktober 2016).

\section{Alasan dan Makna Etnisitas Betawi dalam Siaran Bens Radio}

Alasan mengutamakan nuansa etnik Betawi di radio ini menurut manajer program radio ini, Ririen Aryanti, hal ini disebabkan karena memang radio ini warisan seniman besar Betawi, Benyamin Suaeb. Dialah sosok utama pendiri radio ini. Mendengar cerita dari rekan-rekan Benyamin yang sampai sekarang masih aktif siaran maupun dari pihak keluarga, menurut Ririen, salah satu keresahan Benyamin takut kalau budaya Betawi punah. Generasi sekarang ini berusaha agar Betawi tidak hilang ditelan jaman.

Diakuinya memang sisi kesenian, ragam kesenian Betawi sudah berjalan. Akan tetapi dikhawatirkan kesenian jika tidak diimbangi dengan tersedianya media massa dikhawatirkan akan hilang. Lantas, terpikirlah oleh almarhum Benyamin untuk mendirikan sebuah stasiun radio.

"Waktu itu babe sempat siaran di sebuah radio swasta, lalu terbersitlah ide dari temannya agar dirinya mendirikan radio sendiri. "Kenapa Be, nggak mendirikan radio sendiri?” lalu disarankan radio Betawi yang dapat memutar lagu-lagu gambang kromong, lagu-lagu Betawi dan juga lagunya Benyamin sendiri. Secara kebetulan, saat itu ruang untuk mengudarakan siaran bernuansa Betawi belum ada. Benyamin walaupun dianggap seniman besar namun lagu-lagunya jarang diputar di radio-radio kebanyakan saat itu”. (Wawancara 16 November 2016)

Waktu itu terpikir oleh Benyamin, lanjut Ririen, nama radionya adalah Radio Ondel-Ondel, mengingat jenis kesenian ini menjadi salah satu icon-nya Jakarta. Lalu muncul masukan lagi, mengapa tidak Bens saja, sebab Bens singkatan dari Benyamin Suaeb. Lalu, disetujuilah oleh Benyamin. Menurut informasi, waktu itu Benyamin sendiri juga turut siaran di radio tersebut.
Walaupun Benyamin sosok seniman besar Betawi, namun di radionya ini tidak terusterusan siaran bernuansa Betawi. Bahkan saat itu lagunya Whiney Huston pun juga diputar sesuai permintaan pendengar, ketika salah satu anak Benyamin memintanya untuk memutar lagu tersebut. Sampai sekarang komposisi lagu-lagu Barat juga masih diudarakan, bukan semata lagu-lagu Betawi.

Pengudaraan unsur budaya Betawi di radio ini dapat dimaknai sebagai pelestarian budaya Betawi sesuai pesan almarhum Benyamin Suaeb, agar Betawi jangan sampai punah. Maka dari itu didirikanlah radio sebagai sarana komunikasi untuk masyarakat Betawi dan budaya betawi. Diakui Ririen, godaan ke arah pop itu tetap ada, karena baginya radio itu adalah industri. Dalam hematnya, tidaklah mungkin bertahan dengan murni mengangkat siaran budaya. Artinya, unsur komersil haruslah tetap dikejar, walaupun tetap mengangkat etnik Betawi.

"Jika dipersentase, dilihat dari semuanya isi siaran, bukan hanya dari lagu atau musiknya, nuansa etnik Betawi itu mencapai kisaran 20 persen, sementara yang bersifat pop dan bernuansa kekinian atau tren berada di kisaran 80 persen. Walaupun hanya 20 persen, namun nuansa etnik Betawi diusahakan diperkuat terus menerus. Kalau mau bicara etnik Betawi, tersedia program-programnya. Kita memutar lagu Betawi. Lalu ada juga komunitas yang erat dengan budaya Betawi. Walaupun Bahasa komunikasi penyiar tidak harus semata Betawi. Penyiar Bens Radio tidak semuanya Betawi, lho. Kalau diperhatikan, Betawi dalam Bahasa lebih kepada aksen. Tidak beda dengan sunda atau jawa yang dapat berubah. Betawi memang tetap sama, logatnya saja yang beda.”

Melihat alasan dan makna pengarusutamaan siaran bernuansa Betawi di atas, maka dari itu Bens Radio tidaklah langsung menyuarakan isu keterpinggiran 
masyarakat Betawi yang digambarkan sebagian pihak selama ini. Secara keseluruhan, radio ini berorientasi bukan hanya Betawi, tapi secara umum. Bahkan menurut survey AC Nielsen, Ririn menurskan, Bens Radio ini mempunyai pendengar yang termasuk all greater Jakarta, tanpa membedakan Betawi atau bukan. Unsur Betawi dipertahankan lebih karena kecintaan kepada almarhum Benyamin Suaeb. Lantas, muncul komunitas pecinta Benyamin Suaeb, Benyamin Suaeb Fans Club. Mereka mendengarkan radio ini lebih karena kecintaan mereka kepada almarhum. Fansnya Benyamin juga bukan hanya orang Betawi.

Walaupun hanya menempati kisaran 20 persen dari seluruh program siaran, terdapat beberapa program yang kental unsur Betawi, pertama program asal goblek yang diputar seminggu sekali. Program ini telah ada sejak almarhum Benyamin masih hidup. Siaran itu dulu dibawakan almarhum sendiri yang isinya berupa celetak-celetukannya Benyamin. Di siaran itu dibacakan surat-surat atensi dari pendengar.

"Waktu itu belum ada email. Pendengar bertanya macam hal ke babe, lalu dijawab sekenanya sama babe. Nama siarannya asal goblek, asal jawab saja. Atau tebak-tebakan saja, sampai sekarang tetap dipertahankan. Dalam siaran ini, penyiar musti orang Betawi. Hal ini karena kental nuansa Betawi dan musiknya juga music Betawi, baik music dari benyamin maupun gambang kromong. Komunitas pendengarnya memang juga Betawi.”

Program bernuansa Betawi berikutnya yang perlu dicatat yaitu program Sahibul Hikayat. Isinya seni bertutur atau bercerita dari Betawi. Tokohnya semacam dalam yang dapat bercerita tentang cerita apapun. Misalnya cerita 1001 malam, atau ceritacerita kebetawian. Bersama program asal goblek, program siaran ini yang kental unsur betawinya. Sementara yang lain mungkin Betawi muncul dari sisi dialek. Ada juga program insert, the Batavian. Program ini berisi siaran yang mengupas Jakarta, termasuk nama tempat, makanan, termasuk sejarah Betawi terdapat di dalamnya. Ada juga program kamus Betawi. Istilah-istilah yang memang jarang diketahui banyak orang.

Menurut Ririen, proporsi sejumlah 20 persen unsur Betawi di Bens Radio ini bukanlah untuk strategi jualan, melainkan sebatas untuk mendekatkan komunitas dan positioning radionya. Positioning itu kemudian diwujudkan dalam tagline "Betawi Punya Gaye”. Maksudnya orang Betawi dan budaya Betawi yang mempunyai gaya sekarang, yang kekinian dan mengikuti perkembangan jaman. Begitu pula, strategi mengangkat etnis Betawi ini bukan untuk mengangkat isu terpinggirnya masyarakat Betawi. "Pendalaman kita tidak sampai ke situ. Sekali lagi loyalitas dan kecintaan pendengar terhadap sosok almarhum Benyamin Suaeb saja," terangnya.

Terkait dengan radio komunitas, menurutnya tidak pernah disinggung di Bens Radio. Pihaknya belum pernah mendengar konsep radio komunitas untuk seluruh radio yang bernuansa Betawi. Sepengetahuan dirinya, memang ada juga radio yang menyiarkan lagu-lagu Benyamin, namun itu bagian dari siaran radio mereka. "Kita bukan radio komunitas, kita di FM dan kita tercatat di PRSNI,” lanjutnya.

Untuk memperkuat posisi bisnisnya, mengutip survei AC Nielsen tahun 2016, radio ini disampaikan Ririen menduduki nomor dua jumlah pendengar di Jabodetabek setelah Gen FM. Oleh karena itu, pendengarnya dapat dipastikan bukanah semua orang Betawi karena menyangkut seluruh masyarakat Jabodetabek. Ditambahkannya, keetnikan radio ini juga diwujudkan dalam radio jaringan yang dibentuk sebanyak 12 radio jaringan yang dinamakan Etnikom. Radioradio yang konsepnya etnik. Cirebon dengan etniknya sendiri, Bandung juga 
dengan etniknya sendiri. Begitu juga dengan Palembang. Begitu juga dengan Bens Radio dengan keetnikannya sendiri. Unsur keetnikan muncul itu dikombinasikan dengan kondisi kekinian. Maksudnya bukan untuk mengangkat jatidiri sebuah etnis.

"Jika bicara pure etnik itu, kita tidak bisa hidup. Hanya memposisikan diri radionya Betawi. Ketika di searching di google, yang muncul adalah bens radio. Kalau hanya radio di Jakarta, pasti yang keluarnya kan banyak radio. Namun jika hanya radio Betawi, yang muncul pastilah salah satunya Bens Radio”.

Dirinya pun menuturkan, sayangnya belum pernah dilakukan survei juga, siapa pendengarnya apakah Betawi atau bukan Betawi. Menurutnya tidak pernah dilakukan kegiatan sejauh itu. Waktu dilakukan FGD itu selalu dianggap pendengar Bens Radio adalah all greater Jakarta. Dalam materi siarannya pun, bukan melulu Betawi namun juga dipikiran kemodernan dan juga tren global anak mudanya juga seperti apa.

Untuk memperkuat kedudukannya dalam memposisikan diri sebagai penyuara kesenian dan budaya Betawi, radio ini juga berjejaring dengan lembaga-lembaga terkait, terutama yang pedulu dengan budaya dan kesenian Betawi. Tercatat misalnya, radio ini membangun jaringan dengan lembaga dan ormas Betawi paling kuat misalnya jejaring dengan lembaga Bamus Betawi dan juga Lembaga Kesenian Betawi (LKB). Sifat jaringannnya lebih pada support acara, sewaktu Bamus Betawi ataupun LKB mempunyai acara radio ini mendukung kegiatan tersebut.

\section{KESIMPULAN}

Berdasarkan riset ini, diketahui bahwa dalam kenyataannya, ternyata radio komersial tidak sepi dari lahan mendulang keuntungan. Kehadirannya jelas-jelas didesaian sebagai organisasi profit dengan mengandalkan pemasukan iklan walaupun menyiarakan nuansa etnis ataupun lokal. Di tengah siaran bernuansa etnis tersebut, sangat jelaslah siaran radio komersial dibumbui dengan iklan berbagai produk dan jasa. Berdasarkan narasi tersebut, munculnya siaran bernuansa etnis juga dapat dilihat sebagai cara pengelola radio komersial untuk meraih keuntungan.

Data ini terkonfirmasi ketika menyelami pengelolaan radio MPM Cemerlang dengan siaran bernuansa etnis Jawa-nya. Siaran bernuansa Jawa misalnya, disuarakan karena ditujukan untuk membidik secara khusus pendengar pekerja di wilayah Depok yang berasal dari Jawa. Sedangkan siaran Betawi di Bens Radio lebih untuk memantapkan positioning radio ini di tengah persaiangan antarradio swasta di Indonesia. Walaupun tidak secara khusus menyatakan mengadvocacy suara-suara Betawi, radio Bens sangat memperhatikan kesenian dan budaya Betawi seperti pesan yang disampaikan oleh almarhum pendirinya, Benyamin Suaeb.

\section{DAFTAR PUSTAKA}

Baxter, Pamela \& Jack, Susan. Qualitative Case Study Methodology: Study Design and Implementation for Novice Researchers. The Qualitative Report Volume 13 Number 4 December 2008.

Cankaya, Özden. Güney, H.Serhat \& Köksalan, M.Emre. Turkish radio broadcasts in The Netherlands: Community Communication or Ethnic Market? Westminster Papers in Communication and Culture c 2008 (University of Westminster, London), Vol. 5(1): 86-106. ISSN 1744-6708 (Print); 1744-6716 (Online).

Cottle, Simon (Ed). Ethnic Minorities and The Media. Changing Cultural Boundaries. Buckingham \& 
Philadelphia: Open University Press. 2000.

Hargrave, Andrea Millwood (Ed.). Multicultural Broadcasting: Concept And Reality. London: British Broadcasting Corporation, Broadcasting Standards Commission, Independent Television Commission, Radio Authority. 2002.

Komisi Penyiaran Indonesia Nomor 01/P/Kpi/03/2012 tentang Pedoman Perilaku Penyiaran.

Mahfouz, Safi Mahmoud. America's Melting Pot or the Salad Bowl: The Stage Immigrant's Dilemma. Journal of Foreign Languages, Cultures \& Civilizations, Vol. 1 No. 2, December 2013.

Masduki (et al). Radio Komunitas. Belajar Dari Lapangan. Jakarta: Kantor Perwakilan Bank Dunia di Indonesia. 2007.

Patkin, John \& Stapleton, Paul. 2012. Public Radio and Inclusiveness A Study of Hong Kong's Radio 3 and the South Asian Community. Journal Media Asia, Vol. 39 No 3.

Peraturan Komisi Penyiaran Indonesia Nomor 01/P/KPI/03/2012 tentang Pedoman Perilaku Penyiaran.

Putro, Moh. Zaenal Abidin Eko \& Pratiwi, Nurul Intan. Mengkaji Konsep Kebhinnekaan Dan Kesatuan Serta Proses Belajar Mengajar Mahasiswa Program Kerja Sama Antara Politeknik Negeri Jakarta (PNJ) Dan Pemda Kaimana, Provinsi Papua. Laporan Akhir Penelitian Bidang Ilmu Danpengembangan Institusi (BIL). Politeknik Negeri Jakarta. 2015.

Undang-Undang No 32 tahun 2002 tentang Penyiaran

Vaizey, Ed MP. Action Stations. The Output and Impact Of Commercial Radio.

http://www.radiocentre.org/files/actio n_stations_web.pdf diakses tanggal 26 April 2016.
Internet:

(https://www.merdeka.com/peristiwa/kisah -benyamin-sukses-tinggalkan-bisnisradio-untuk-anak-anaknya.html, diakses tanggal 18 Oktober 2016). 
